Vol 11, Issue 4, 2018

\title{
INHIBITORY EFFECT OF A STANDARDIZED HYDROETHANOLIC EXTRACT OF TERMINALIA ARJUNA BARK ON ALPHA-AMYLASE ENZYME
}

\author{
SUSHANT A SHENGULE ${ }^{1}$, SANJAY MISHRA ${ }^{1 *}$, SHWETA BODHALE ${ }^{2}$ \\ ${ }^{1}$ Dr. Prabhakar Kore Basic Science Research Center, KLE Academy of Higher Education and Research, Belagavi, Karnataka, India. \\ ${ }^{2}$ Interdisciplinary School of Health Sciences, Savitribai Phule Pune University, Pune, Maharashtra, India. \\ Email: bt.sanjay@gmail.com
}

Received: 29 November 2017, Revised and Accepted: 12 January 2018

ABSTRACT

Objective: The present study was initiated to screen the hydroethanolic bark extract for $\alpha$-amylase inhibitory activity and standardization of the Terminalia arjuna for polyphenolic phytochemicals using high-performance liquid chromatography-photo diode array (HPLC-PDA) method.

Methods: The T. arjuna bark sample was extracted with ethanol: water (70:30 v/v) using Soxhlet extraction. A Dionex P680 HPLC system was used to acquire chromatograms. The screening of extract of T. arjuna bark has performed for in vitro $\alpha$-amylase inhibitory assay. Each experiment was repeated 3 times. All values were expressed mean \pm standard deviation.

Results: The content of arjunetin, arjungenin, gallic acid, ellagic acid, and quercetin was $0.47,8.22,2.443,7.901$, and 3.20 mg/g, respectively, in a hydroethanolic extract of T. arjuna. The hydroethanolic extract of T. arjuna bark and acarbose has shown an inhibitory activity with an $\mathrm{IC}_{50}$ value 145.90 and $62.35 \mu \mathrm{g} / \mathrm{mL}$, respectively.

Conclusion: The hydroethanolic extract T. arjuna bark demonstrates $\alpha$-amylase inhibitory activity due to a synergistic effect of the phytochemical constituents present in it. This study suggests that one of the mechanisms of this plant for antidiabetic activity is through the inhibition of $\alpha$-amylase enzyme.

Keywords: Terminalia arjuna, Acarbose, Diabetes, Enzyme inhibition, Arjunetin, Arjungenin.

(c) 2018 The Authors. Published by Innovare Academic Sciences Pvt Ltd. This is an open access article under the CC BY license (http://creativecommons. org/licenses/by/4. 0/) DOI: http://dx.doi.org/10.22159/ajpcr.2018.v11i4.24019.

\section{INTRODUCTION}

Diabetes mellitus (DM) is a complex disease developed due to unbalanced carbohydrate, protein, and fat metabolism. A progressive metabolic disorder finally leads to micro- and macro-vascular changes causing secondary complications [1]. According to the World Health Organization, 346 million people worldwide have diabetes and among $90 \%$ of them suffer from type 2 diabetes (T2DM) [2,3]. Type 1 diabetes results from the deficient synthesis of insulin by $\beta$-cells of the pancreas, while T2DM is developed due to insulin resistance condition or $\beta$-cell dysfunction [1].

The treatment of T2DM is based on oral antidiabetic drugs include sulfonylureas, biguanides, and thiazolidinediones. However, they have demonstrated some side effects which suggest the need for other alternative therapy [4-6]. One of the treatment approaches is to decrease the after-meal blood glucose concentrations [5]. Inhibition of the $\alpha$-amylase enzyme in the intestine delays the degradation of starch before absorption that reduces postprandial blood glucose concentrations $[4,7]$.

Voglibose, acarbose, and Miglitol are the $\alpha$-amylase inhibitory drugs available in the market. These are prescribed as combinatorial therapy with sulfonylurea and metformin for the treatment of T2DM to reduce glycated hemoglobin (HbA1c) levels. However, the previous studies have reported few side effects such as abdominal discomfort, flatulence, and diarrhea for these drugs [8]. The side effects caused and drug resistance is two major concerns in the usage of these drugs after prolonged treatment [2].

Traditional medicinal plants have used to treat various diseases. Plant extracts or phytochemical constituents have been reported scientifically for biological activities [5]. Terminalia arjuna Roxb. (Combretaceae) commonly known as Arjuna, has been traditionally used for several medicinal purposes such as cardiac diseases, dyslipidemia, and lowering blood glucose [9-11]. The hydroethanolic extracts of the T. arjuna (TAHA) leaves and stem bark have been reported to possess anti-diabetic activities in diabetic rats $[9,12]$. The previous study by Saha et al. have reported the $\alpha$-amylase inhibitory activity of methanolic, aqueous and $50 \%$ methanolic extract of T. arjuna $[13,14]$. While there is no evidence in the literature that has determined TAHA bark extract containing arjunetin, arjungenin, ellagic acid, gallic acid, and quercetin compounds for $\alpha$-amylase inhibition activity. This study will be useful to determine one of the possible mechanisms of effect of TAHA as antidiabetic activity. Therefore, the objective of the present study was to screen the inhibitory activity of TAHA bark extract for $\alpha$-amylase enzyme and standardization for polyphenolic phytochemicals using high-performance liquid chromatography-photo diode array (HPLC-PDA) method.

\section{MATERIALS AND METHODS}

\section{Materials/chemicals}

Solvents such as HPLC grade methanol and acetonitrile (Merck, Mumbai, and India) were used to prepare samples and mobile phase, respectively. Water was purified using the Milli-Q (Millipore, Billerica, MA) system. Arjunetin, arjungenin, gallic acid, ellagic acid, and quercetin were purchased as HPLC markers from the Natural Remedies Pvt. Ltd. Bangalore, India. Enzyme $\alpha$-Amylase was purchased from Sigma-Aldrich, Bangalore, India.

\section{Plant material and extraction}

The T. arjuna bark sample was collected from a local market in Pune, India, and authenticated by Agharkar Research Institute, Pune, India. The sample was deposited as voucher specimens no. S/B-109. The dried bark was extracted with ethanol: water $(70: 30 \mathrm{v} / \mathrm{v})$ using Soxhlet 
extraction for $8 \mathrm{~h}$ for consecutive 3 days at $65^{\circ} \mathrm{C}$. The extract was dried under vacuum using rotary evaporator at $45^{\circ} \mathrm{C}$ and stored at $2-8^{\circ} \mathrm{C}$ until use.

\section{Estimation of arjunetin and arjungenin in a TAHA bark extract} A Dionex P680 HPLC system including autosampler and thermostatted column compartment and a Dionex UVD 170U/340U photodiode array detector (Dionex Corp., Germering, Germany) was used to acquire chromatograms. The column used was RP C18 BDS Hypersil column $(250 \times 4.6 \mathrm{~mm}, 5 \mu \mathrm{m}$ particle size $)$ from Thermo Electron Corp. (Bellefonte, PA). Chromeleon 6.70 software from Dionex was used to acquire data for fingerprint analysis.

The analysis was performed with an RP C18 BDS Hypersil column $(250 \times 4.6 \mathrm{~mm}, 5 \mu \mathrm{m}$ particle size $)$ at a column temperature $26^{\circ} \mathrm{C}$. The gradient program for pump A (acetonitrile: water, 30:70) and pump $\mathrm{B}$ (acetonitrile: water, $70: 30$ ) as follows: Initially $30 \% \mathrm{~B}$, flow rate $0.8 \mathrm{ml} / \mathrm{min}$; increased gradually to $50-70 \% \mathrm{~B}$ up to $30 \mathrm{~min}$, flow rate $1.2 \mathrm{ml} / \mathrm{min}$, then $20 \mathrm{~min}, 30 \% \mathrm{~B}$, flow rate $0.8 \mathrm{ml} / \mathrm{min}$. The detection wavelength was $220 \mathrm{~nm}$. Injection volume for standard and sample was $20 \mu \mathrm{l}$ [15]. Data analysis was performed by variations and similarity observed in retention time values, peak areas and spectral patterns of the peaks obtained in the chromatograms of T. arjuna bark extract.

\section{Estimation of ellagic acid, gallic acid, and quercetin in a TAHA bark} extract

Phytochemical characterization was carried out using gallic acid, ellagic acid, and quercetin by HPLC method [16-18]. Briefly, prominence HPLC system (Shimadzu, Japan) was used. Chromatographic separations were carried out using C-18 column $(150 \times 4.6 \mathrm{~mm}, 5 \mu \mathrm{m}$ particle size; Syncronis, Thermo Scientific, USA). Following gradient elution with water containing $0.5 \%$ acetic acid (component $\mathrm{A}$ ) and acetonitrile: water containing $0.5 \%$ of acetic acid $(80: 20 \mathrm{v} / \mathrm{v})$ as component B was used.

The nonlinear gradient elution program: $0-10 \mathrm{~min} 10 \%$ of B; $10-20 \mathrm{~min}$ $20 \%$ of B; $20-30$ min $40 \%$ of B; $30-40$ min $60 \%$ of B; $40-45 \min 70 \%$ of B; and $45-55 \mathrm{~min} 10 \%$ of $B$ and equilibrated with initial conditions for another $5 \mathrm{~min}$. The flow rate and oven temperature were used at $1.0 \mathrm{ml} / \mathrm{min}$ and $25^{\circ} \mathrm{C}$, respectively. All chromatograms were monitored at $270 \mathrm{~nm}$.

\section{Assay of alpha-amylase inhibition}

A mixture of $50 \mu \mathrm{l}$ of extract or acarbose and $50 \mu \mathrm{l} 0.02$ mol sodium phosphate solution ( $\mathrm{pH} 6.9$ with $6 \mathrm{mmol}$ sodium chloride) containing alpha-amylase solutions $(13 \mathrm{U} / \mathrm{ml})$ were incubated at $25^{\circ} \mathrm{C}$ for $10 \mathrm{~min}$. After pre-incubation, $50 \mu \mathrm{l} 1 \%$ soluble starch solution in $0.02 \mathrm{~mol}$ sodium phosphate solution ( $\mathrm{pH} 6.9$ with $6 \mathrm{mmol} \mathrm{NaCl}$ ) was added to each well at timed intervals. The reaction mixtures were then incubated at $25^{\circ} \mathrm{C}$ for $10 \mathrm{~min}$ followed by addition of $1 \mathrm{ml}$ dinitrosalicylic acid color reagent. Then, the test tubes were placed in hot water (at $80^{\circ} \mathrm{C}$ for $10 \mathrm{~min}$ ) to stop the reaction. The reaction mixture was diluted with $1 \mathrm{ml}$ distilled water and absorbance was read at $540 \mathrm{~nm}[19,20]$.

\section{Statistical analysis}

Each experiment was repeated 3 times, and the data averaged for reporting. All values were expressed mean \pm standard deviation (SD). Percentage of inhibition was calculated using the formula:

$\%$ Inhibition $=[($ Abs control - Abs sample $) /$ Abs control $] * 100$

The $\mathrm{IC}_{50}$ values were determined through nonlinear regression by fitting to a sigmoid dose-response equation with variable slope using GraphPad Prism5 software (GraphPad Software, Inc. La Jolla, CA, USA)

\section{RESULTS}

Phytochemical standardization of TAHA bark extract

Phytochemical standardization of TAHA extract was carried out using selected marker-based approach. Arjunetin, arjungenin, gallic acid, ellagic acid, and quercetin were used as phytochemical markers for standardization purpose. The marker contents were estimated using earlier reported HPLC-PDA method suitably modified on column and mobile phase gradient. The optimized chromatographic conditions showed good resolution of the all the peaks. The presence of marker contents in the TAHA extract was identified using retention time and ultraviolet (UV) spectra matching with corresponding reference standards. The retention time for arjunetin and arjungenin was found to be 4.95 and $7.68 \mathrm{~min}$, respectively. The $t_{\mathrm{R}}$ for gallic acid, ellagic acid, and quercetin was found to be $2.36,24.71$, and $31.98 \mathrm{~min}$, respectively. The spectral overlays for arjunetin and arjungenin showed the presence of UV spectra at $220 \mathrm{~nm}$. The spectral overlays for gallic acid, ellagic acid, and quercetin showed the presence of UV spectra at $270 \mathrm{~nm}$. The calibration plots of arjunetin and arjungenin versus peak area were constructed in the range of $31.25-1000 \mu \mathrm{g} / \mathrm{ml}$. The calibration plots of gallic acid, ellagic acid, and quercetin versus peak area were constructed in the range of 3.125-100 $\mu \mathrm{g} / \mathrm{ml}$. The content of arjunetin and arjungenin was 0.47 and $8.22 \mathrm{mg} / \mathrm{g}$ in the TAHA extract (Table 1). These quantitative estimations were consistent with earlier reports on a TAHA extract. The content of gallic acid, ellagic acid, and quercetin was $2.443 \pm 0.090,7.901 \pm 0.786$, and $3.20 \pm 0.351 \mathrm{mg} / \mathrm{g}$, respectively, in the TAHA extract (Table 1). These quantitative estimations were consistent with earlier reports of a TAHA extract.

\section{Effect of TAHA extract and acarbose on $\alpha$-amylase activity}

In this study, acarbose is used as a standard drug for $\alpha$-amylase inhibitor assay. Acarbose (at a concentrations $5-160 \mu \mathrm{g} / \mathrm{ml}$ ) showed $\alpha$-amylase inhibitory activity from $7.57 \pm 1.40$ to $76.86 \pm 3.72 \%$ with an $\mathrm{IC}_{50}$ value $62.35 \pm 5.39 \mu \mathrm{g} / \mathrm{ml}$ (Table 2)

The percentage inhibition of the TAHA extract on $\alpha$-amylase enzyme was studied in a concentration range of $10-320 \mu \mathrm{g} / \mathrm{ml}$. The TAHA extract has shown inhibition of from $8.43 \pm 1.51$ to $71.00 \pm 4.66 \%$ with an $\mathrm{IC}_{50}$ value $145.90 \pm 16.34 \mu \mathrm{g} / \mathrm{ml}$. The IC $\mathrm{IC}_{50}$ value for a TAHA extract was $145.90 \pm 16.34 \mu \mathrm{g} / \mathrm{ml}$ which is lesser to standard anti-diabetic drug acarbose which was $62.35 \pm 5.39 \mu \mathrm{g} / \mathrm{ml}$ (Table 2).

\section{DISCUSSION}

Many herbal extracts have reported and used in Ayurveda for the treatment of diabetes. However, medicinal plants have not gained much importance due to lack of proper standardization of herbal medicines and scientific support [5].

Several reports on the phytochemical analysis of T. arjuna have been recently published. The major isolated compounds include the five oleane derivatives, namely, arjunic acid, arjunolic acid, arjungenin, arjunetin, and arjunglucoside I from stem bark extract [21]. Also, flavon3 -ols such as (+)-catechin, (+)-gallocatechin, and (-)-epigallocatechin; phenolic acids such as gallic acid, ellagic acid and its derivatives such as 3-0-methyl-ellagic acid 4-0- $\beta$-D-xylopyranoside, and 3-0-methyl ellagic acid 3-0-rhamnoside were reported [22]. However, not much data are available related to $\alpha$-amylase inhibition.

Effective synthetic $\alpha$-amylase inhibitors (acarbose and voglibose) are available but cause various negative gastrointestinal symptoms

Table 1: Quantitation of arjunetin and arjungenin in the TAHA extract

\begin{tabular}{llll}
\hline $\begin{array}{llll}\text { Compound } \\
\text { name }\end{array}$ & \multicolumn{2}{l}{ Rt (min) } & (mg/g of TAHA) \\
\cline { 2 - 3 } & $\begin{array}{l}\text { Reference } \\
\text { standard }\end{array}$ & TAHA & \\
\hline Arjunetin & $4.95 \pm 0.0$ & $5.09 \pm 0.02$ & $0.59 \pm 0.04$ \\
Arjungenin & $7.69 \pm 0.0$ & $7.88 \pm 0.04$ & $0.85 \pm 0.01$ \\
Gallic acid & $2.36 \pm 0.0$ & $2.36 \pm 0.05$ & $2.44 \pm 0.09$ \\
Ellagic acid & $24.71 \pm 0.0$ & $24.71 \pm 0.06$ & $7.90 \pm 0.79$ \\
Quercetin & $31.99 \pm 0.0$ & $31.97 \pm 0.1$ & $3.20 \pm 0.35$ \\
\hline
\end{tabular}

Results were expressed as mean \pm SD; $n=6$, SD: Standard deviation 
Table 2: Effect of acarbose and TAHA extract for $\alpha$-amylase inhibitory activity

\begin{tabular}{llll}
\hline Drug/extract & Concentration of acarbose $(\mu \mathrm{g} / \mathbf{m l})$ & \% of inhibition & IC $_{50} \mathbf{v a l u e ~}(\boldsymbol{\mu g} / \mathbf{m l})$ \\
\hline Acarbose & 0 & 0 & $62.35 \pm 5.39$ \\
& 5 & $7.57 \pm 1.40$ & \\
& 10 & $15.43 \pm 1.27$ & \\
& 20 & $23.71 \pm 1.60$ & \\
TAHA & 40 & $59.00 \pm 2.65$ & $145.90 \pm 16.34$ \\
& 0 & $76.86 \pm 3.72$ & \\
& 160 & 0 & \\
& 10 & $8.43 \pm 1.51$ & $13.71 \pm 1.60$ \\
\\
20 & $20.86 \pm 2.34$ & $33.43 \pm 5.06$ & \\
& 40 & $50.86 \pm 2.67$ & \\
\end{tabular}

Results were expressed as mean \pm SD; experiments were performed 3 times in triplicate; $n=9$, SD: Standard deviation

and hepatic disorders [23,24]. Phenolic $\alpha$-amylase inhibitors from herbal extracts are potentially safer, and therefore, may be a suitable alternative for inhibition of carbohydrate breakdown and control of glycemic index of food products.

While there is no published report in the literature to date that has tested TAHA extract containing arjunetin, arjungenin, ellagic acid, gallic acid, and quercetin compounds for $\alpha$-amylase inhibition activity. However, the methanolic, aqueous and $50 \%$ methanolic extract of T. arjuna was reported for $\alpha$-amylase inhibition activity [13,14]. Table 2 represents the inhibitory effect of different concentration of the TAHA extract and acarbose. A TAHA extract and acarbose exhibited $\alpha$-amylase inhibitory effects with an $\mathrm{IC}_{50}$ value of $145.90 \pm 16.34$ and $62.35 \pm 5.39 \mu \mathrm{g} / \mathrm{ml}$. In this study, acarbose $(10-160 \mu \mathrm{g} / \mathrm{ml})$ extract has shown an inhibition ranging from $15 \%$ to $76 \%$ and $T$. arjuna $(10-160 \mu \mathrm{g} / \mathrm{ml})$ though exhibited a minimum inhibitory potential ranging from $8 \%$ to $50 \%$ against $\alpha$-amylase, it was less and not statistically significant. These investigations suggest that this may be due to the presence of potential $\alpha$-amylase inhibitors.

In a recent study, methanol and free flavonoids extract of T. arjuna has been reported for $\alpha$-amylase inhibitory effects with an $\mathrm{IC}_{50}$ valve 5.16 and $38.28 \mathrm{mg} / \mathrm{ml}$ [13]. Previously, Saha et al., reported that methanolic, aqueous and $50 \%$ methanolic extract of T. arjuna showed $\alpha$-amylase inhibitory activity. $\mathrm{IC}_{50}$ value of methanolic, aqueous and $50 \%$ methanolic extract of T. arjuna was $1503 \pm 0.71 \mu \mathrm{g} / \mathrm{ml}, 592 \pm 0.34 \mu \mathrm{g} / \mathrm{ml}$, and $302 \pm 0.55 \mu \mathrm{g} / \mathrm{ml}[14]$. Further, our results suggest that the health promoting benefits of T. arjuna herbs used in traditional Indian medicine for treatment of DM may involve the $\alpha$-amylase inhibiting activity of polyphenolic compounds, and that $\alpha$-amylase inhibiting activity may be promoted by mechanistic synergies among the present phenolic substances.

Previous studies on the in vivo antidiabetic potential of T. arjuna bark in Wistar rats concluded that the hydroethanolic extract of this plant possessed strong glucose-lowering property in both alloxan and streptozotocin-induced diabetic rats $[12,25]$, but the mechanism of action remained elusive. The present study suggests that one of the mechanisms by which T. arjuna exhibited its hypoglycemic potential in the reported animal study is through the inhibition of $\alpha$-amylase. This inhibitory activity of the TAHA extract might be due to the presence of several polyphenols such as arjungenin, arjunetin, arjunolic acid, arjunic acid, quercetin, gallic acid, and ellagic acid in it.

The results of this study direct further research to evaluate the therapeutic effect of T. arjuna in the management of postprandial hyperglycemia in T2DM either alone or a combinatorial therapy. Further research is needed to investigate the potential $\alpha$-amylase inhibitory activity of polyphenolic compounds present in T. arjuna and at elucidating putative phenolic synergies that may promote inhibition of $\alpha$-amylase activity.

\section{CONCLUSION}

The TAHA bark extract demonstrates good $\alpha$-amylase inhibitory activity due to a synergistic effect of the phytochemicals present in it. This study suggests that one of the mechanisms by which this plant displayed its antidiabetic potential is by the inhibition of $\alpha$-amylase.

\section{ACKNOWLEDGMENT}

We acknowledge Prof. Sunil Jalalpure, Director of Dr. Prabhakar Kore Basic Science Research Centre, KLE University, for approval to use the facility.

\section{AUTHORS CONTRIBUTION}

Shushant A Shengule, has majorly performed the experiments in the laboratory. Sanjay Mishra, has provided the experimental concept, data analysis, and sincerely authored the article. Shweta Bodhale, has role for experimental protocol and conducting the experiment along with mentorship.

\section{CONFLICTS OF INTEREST}

The authors declare that there is no conflict of interest regarding the publication of this article.

\section{REFERENCES}

1. Kazeem MI, Adamson JO, Ogunwande IA. Modes of inhibition of $\alpha$-amylase and $\alpha$-glucosidase by aqueous extract of Morinda lucida Benth Leaf. BioMed Res Inter 2013;527570:6.

2. Jyothi KS, Hemalatha P, Avanthi A, Challa S. A comparative analysis on the alpha amylase inhibitory potential of six ornamental medicinal plants. J Nat Prod Plant Resour 2013;3:1-6.

3. Prabu M, Kumuthakalavalli R. Antidiabetic potential of the oyster mushroom Pleurotus florida (mont.) singer. Int J Curr Pharm Res 2017;9:51-4

4. Shareef MI, Reddy PJ, Gopinath SM, Dayananda KS, Mandal A, Purushotham KM. In vitro $\alpha$-amylase inhibitory activity of the leaves of Tinospora cordifolia. Inter J Innovat Res in Sci Eng Tech 2014;3:10091-6.

5. Dineshkumar B, Mitra A, Manjunatha M. A comparative study of alpha amylase inhibitory activities of common anti-diabetic plants at kharagpur 1 block. Inter J of Green Pharm 2010;4:115-21.

6. Rupeshkumar M, Kunchu K, Pallab H. Role of herbal plants in the diabetes mellitus therapy: An overview. Int J App Pharm 2014;6:1-3.

7. Reka P, Thahira B, Seethalakshmi M. Alpha amylase and alpha glucosidase inhibition activity of selected edible seaweeds from south coast area of India. Int J Pharm Pharm Sci 2017;9:64-8.

8. Chakrabarti R, Singh B, Prakrith VN, Vanchhawng L, Thirumurugan K. Screening of nine herbal plants for in vitro a-amylase inhibition. Asian $\mathrm{J}$ Pharm Clin Res 2014;7:84-9.

9. Biswas M, Kar B, Bhattacharya S, Kumar RB, Ghosh AK, Haldar PK. Antihyperglycemic activity and antioxidant role of Terminalia arjuna leaf in streptozotocin-induced diabetic rats. Pharm Biol 2011;49:335-40. 
10. Dube N, Nimgulkar C, Bharatraj DK. Validation of therapeutic antiinflammatory potential of arjuna ksheera paka: A traditional ayurvedic formulation of Terminalia arjuna. J Trad Complem Med 2017;7:414-20.

11. Desai S, Patil B, Kanthe P, Potekar R. Effect of ethanolic extract of Terminalia arjuna on liver functions and histopathology of liver in albino rats fed with hyperlipidemic diet. Int $\mathrm{J}$ Pharm Pharm Sci 2015;7:302-6.

12. Ragavan B, Krishnakumari S. Effect of Terminalia arjuna stem bark extract on the activities of marker enzymes in alloxan induced diabetic rats. Anc Sci Life 2005;25:8-15.

13. Jaiswal P, Kumar P. Alpha amylase inhibitory activity of different extract of Terminalia arjuna bark. Curr Trends Biotech Pharm 2017;11:253-8.

14. Saha S, Verma R. Inhibitory potential of traditional herbs on $\alpha$-amylase activity. Pharm Bio 2012;50:326-31.

15. Singh DV, Verma RK, Singh SC, Gupta MM. RP-LC determination of oleane derivatives in Terminalia arjuna. J Pharma Biomed Anal 2002;28:447-52

16. Lal UR, Tripathi SM, Jachak SM, Bhutani K, Singh I. HPLC analysis and standardization of arjunarishta - An ayurvedic cardioprotective formulation. Sci Pharm 2009;77:605-16.

17. Shengule SA, Mishra S, Joshi K, Apte K, Patil D, Kale P, et al. Antihyperglycemic and anti-hyperlipidaemic effect of Arjunarisht in highfat fed animals. J Ayurveda Integr Med 2017; DOI.org/10.1016/j. jaim.2017.07.004

18. Das P, Panneerselvam T, Prabhu P, Reddy J. Method development and validation of gallic acid and ellagic acid in Argwadharistam. Int J Curr
Res 2017;9:61417-20

19. Apostolidisa E, Lib L, Leea C, Seeramb NP. In vitro evaluation of phenolic-enriched maple syrup extracts for inhibition of carbohydrate hydrolyzing enzymes relevant to Type 2 diabetes management. J Funct Foods 2011;3:100-6.

20. Dada FA, Oyeleye SI, Ogunsuyi OB, Olasehinde TA, Adefegha SA, Oboh G, et al. Phenolic constituents and modulatory effects of Raffia palm leaf (Raphia hookeri) extract on carbohydrate hydrolyzing enzymes linked to Type-2 diabetes. J Trad Complem Med 2017;7:494500 .

21. Singh DV, Verma RK, Gupta MM, Kumar S. Quantitative determination of oleane derivatives in Terminalia arjuna by high performance thin layer chromatography. Phytochem Anal 2002;13:207-10.

22. Saha A, Pawar VM, Jayaraman S. Characterisation of polyphenols in Terminalia arjuna bark extract. Indian J Pharm Sci 2012;74:339-47.

23. Sudha P, Zinjarde SS, Bhargava SY, Kumar AR. Potent $\alpha$-amylase inhibitory activity of Indian ayurvedic medicinal plants. BMC Compl Altern Med 2011;11:5.

24. Chipiti T, Ibrahim MA, Singh M, Islam MS. In vitro $\alpha$-amylase and $\alpha$-glucosidase inhibitory effects and cytotoxic activity of Albizia antunesiana extracts. Pharmacogn Mag 2015;11:S231-6.

25. Khaliq F, Parveen A, Singh S, Gondal R, Hussain ME, Fahim M. Improvement in myocardial function by Terminalia arjuna in streptozotocin-induced diabetic rats: Possible mechanisms. J Cardiovasc Pharmacol Ther 2013;18:481-9. 